\title{
Ontogeny of dipeptide uptake and peptide transporter 1 (PepT1) expression along the gastrointestinal tract in the neonatal Yucatan miniature pig
}

\author{
Matthew G. Nosworthy, Robert F. Bertolo and Janet A. Brunton* \\ Department of Biochemistry, Memorial University of Newfoundland, Saint John's, NL, Canada A1B $3 X 9$ \\ (Submitted 20 April 2012 - Final revision received 6 September 2012 - Accepted 14 October 2012 - First published online 12 December 2012)
}

\section{Abstract}

The $\mathrm{H}^{+}$-coupled transporter, peptide transporter 1 (PepT1), is responsible for the uptake of dietary di- and tripeptides in the intestine. Using an in vivo continuously perfused gut loop model in Yucatan miniature pigs, we measured dipeptide disappearance from four $10 \mathrm{~cm}$ segments placed at equidistant sites along the length of the small intestine. Pigs were studied at 1, 2, 3 (suckling) and 6 weeks (post-weaning) postnatal age. Transport capability across the PepT1 transporter was assessed by measuring the disappearance of ${ }^{3} \mathrm{H}$-glycylsarcosine; real-time RT-PCR was also used to quantify PepT1 mRNA. Each of the regions of intestine studied demonstrated the capacity for dipeptide transport. There were no differences among age groups in transport rates measured in the most proximal intestine segment. Transport of ${ }^{3} \mathrm{H}$-glycylsarcosine was significantly higher in the ileal section in the youngest age group (1 week) compared with the other the suckling groups; however, all suckling piglet groups demonstrated lower ileal transport compared with the post-weaned pigs. Colonic PepT1 mRNA was maximal in the earliest weeks of development and decreased to its lowest point by week 6 . These results suggest that peptide transport in the small intestine may be of importance during the first week of suckling and again with diet transition following weaning.

Key words: Glycylsarcosine: Intestinal loops: Ontogeny: SLC15A1: PepT1

Dietary protein is absorbed from the intestinal lumen as its constituent amino acids as well as small peptides containing two or three residues. The protein responsible for dietary di- and tripeptide transport is peptide transporter 1 (PepT1), a member of the proton-coupled oligopeptide transporter super-family of proteins ${ }^{(1)}$. PepT1 is localised to the apical membrane of intestinal villi, allowing it access to the digesta passing through the lumen. Studies that have investigated PepT1 mRNA at distinct regions along the intestine have reported variable results ${ }^{(2-4)}$, probably due to different animal models. In rats and mice, the amount of PepT1 mRNA does not change across the length of the small intestine ${ }^{(5-7)}$; however, in the developing chick intestine, the highest quantities were found in the duodenum and jejunum ${ }^{(3)}$. In adult human subjects and rats, higher concentrations of PepT1 mRNA in the duodenum and jejunum have also been reported ${ }^{(8,9)}$. In contrast, Chen et al. ${ }^{(2)}$ reported similar expression of PepT1 mRNA across the entire length of the small intestine of mature sheep, dairy cows, pigs and chickens.

Few studies have reported the developmental changes in PepT1. Differences in the location and concentration of PepT1 mRNA along the small intestine with increasing age have been reported in rats ${ }^{(10)}$ and chickens ${ }^{(11,12)}$. PepT1 protein increased linearly with age in chickens, but there was a decrease in PepT1 mRNA in rats between postnatal days 4 and 50. Shen et al. ${ }^{(10)}$ demonstrated that even though PepT1 mRNA expression was at its highest point at $3-5 \mathrm{~d}$ after birth in a neonatal rat model, it declined rapidly at all locations in the small intestine during the following days of suckling, suggesting that PepT1 and peptide transport are potentially important in the early life of the suckling neonate. In piglets, D'Inca et $a{ }^{(13)}$ determined that there was a dramatic decrease in PepT1 mRNA expression within the first $48 \mathrm{~h}$ after birth; however, intra-uterine growth restriction delayed this adaptation, further supporting the importance of peptide transport in the newborn.

In adult human subjects, a significant proportion of amino acids are absorbed as di- and tripeptides, and dipeptides are absorbed faster than free amino acids in the jejunum due to the high capacity for uptake by PepT $1^{(14)}$. A high turnover rate and expression level of PepT1 contributes to the rapid uptake of peptides ${ }^{(15)}$. The efficiency in uptake of small peptides combined with the lower osmolarity of peptide solutions support the use of peptides rather than free amino acids in therapeutic enteral formulas ${ }^{(16)}$. In neonates, proteolytic

Abbreviation: PepT1, peptide transporter 1.

*Corresponding author: Dr J. A. Brunton, fax +1 709864 2422, email jbrunton@mun.ca 
capacity is not as well-developed as in adults, due to a significantly lower production of pepsin ${ }^{(17)}$ and trypsin ${ }^{(18)}$. Compared with adults, a higher proportion of amino acids would be present in the neonatal gut as small peptides. As such, the capacity for peptide transport may be high to support optimal nutritional status and growth.

Indeed, alanyl-glutamine is currently being studied as a potential dietary supplement, and has been reported to increase the nutritive status and intestinal barrier function in human neonates ${ }^{(19)}$ as well as to aid in the maintenance of cellular glutathione concentrations during oxidative stress $^{(20)}$. Although the absorption of small peptides is important in healthy individuals, the bioavailability of peptides in times of intestinal duress may be of particular importance. In addition, the added benefits of stability, hypotonicity and palatability $^{(21)}$ support the importance and usefulness of dipeptide preparations for modern clinical treatments.

Characterising the ontogeny of PepT1 in the neonate is of tremendous importance for the development of effective feeding strategies for both healthy and sick infants. The piglet is an excellent model for the human neonates, especially preterm infants $^{(22)}$. Neonatal pigs share similar patterns of intestinal development with human subjects, as well as similar nutritional requirements. Dipeptide transport capacity via PepT1 and the effects of development have not been previously reported in this model. In the present study, we determined PepT1 transport capabilities and relative quantities of PepT1 mRNA at specific locations along the gastrointestinal tract of piglets during suckling and post-weaning.

\section{Experimental methods}

\section{In situ perfusion (gut loop model)}

A total of sixteen Yucatan miniature piglets ( $n 4$ per group) were obtained from the breeding herd at the Memorial University of Newfoundland (average birth weight 1.01 (sem 0.03) kg; average growth rate from birth to 1 month of age: 45 (SEM 3) g/ kg body weight per/d). All procedures were approved by the Institutional Animal Care Committee and were in accordance with the guidelines of the Canadian Council on Animal Care. Piglets were studied at 1, 2, 3 or 6 weeks of age. Piglets in this herd are weaned at 4 weeks of age to a standard pelleted grower pig diet based on wheat, barley, oats and rapeseed meal (15.6\% crude protein, $3.75 \%$ crude fat, $12.1 \mathrm{MJ} / \mathrm{kg}$ digestible energy) (Eastern Farmers Co-op); pre-weaning piglets were exclusively suckled by sows that were fed a typical lactation diet with $14 \%$ crude protein and $3 \%$ crude fat. To avoid fasting (which may alter PepT1 expression or function), the in situ study was initiated within $2 \mathrm{~h}$ of separating the piglets from the sows at 1 , 2 or 3 weeks of age and within $2 \mathrm{~h}$ of last feed for 6 week-old piglets. Anaesthesia was administered with an intramuscular injection of $22 \mathrm{mg} / \mathrm{kg}$ ketamine hydrochloride (Bimeda-MTC) plus $0.5 \mathrm{mg} / \mathrm{kg}$ acepromazine (Vétoquinol Canada, Inc.). General anaesthesia was maintained with $1-2 \%$ isoflurane (Abbot Laboratories Limited), delivered with 1.5 litres $\mathrm{O}_{2} / \mathrm{min}$. Body temperature was maintained via a homoeothermic blanket system that automatically adjusted heat output in response to a rectal temperature probe (Harvard Apparatus). A mid-line incision was made in the abdomen to open the peritoneum. The complete length of the small intestine was measured and four equidistant regions were marked for loop placement. The most proximal jejunal loop (0\%) was defined as $15 \mathrm{~cm}$ from the ligament of Treitz. Closed loops of intestine consisted of $10 \mathrm{~cm}$ sections of intestine, with inlet and outlet cannulas (inner diameter, $0.2 \mathrm{~cm}$; outer diameter, $0.3 \mathrm{~cm}$; Watson Marlow) inserted through a small perforation at both ends of the $10 \mathrm{~cm} \mathrm{sec-}$ tion. In total, four loops were placed at $0,25,50$ and $75 \%$ of the length of the small intestine. Each isolated gut loop was perfused with a dipeptide-containing buffer that was re-circulated through the loop for the duration of the study by a multi-channel peristaltic pump (Watson Marlow). The perfusate $(65 \mathrm{ml})$ contained $5 \mathrm{mmol} / \mathrm{l}$ glycylsarcosine with $37 \mathrm{kBq}{ }^{3} \mathrm{H}$-glycylsarcosine (Moravek) in PBS (144.6 mM-NaCl, $15.9 \mathrm{~mm}-\mathrm{Na}_{2} \mathrm{HPO}_{4}, 1.2 \mathrm{~mm}-$ $\mathrm{NaH}_{2} \mathrm{PO}_{4} ; \mathrm{pH} 6.0$ ), and was maintained at $37^{\circ} \mathrm{C}$ for the duration of the study. Perfusions through each closed loop continued for $120 \mathrm{~min}$. A $1 \mathrm{ml}$ sample of perfusate from each closed loop was removed at every $10 \mathrm{~min}$ to determine isotope disappearance. During the procedure, the exposed intestines were kept moist with warmed saline and covered with gauze and plastic wrap. Heart rate and blood oxygenation were monitored via pulseoximetry (Surgivet) throughout the experiment. At the end of the perfusion period, the loops were excised by cautery, flushed with cold $0.9 \%$ saline, placed on ice, cut longitudinally and scraped with a microscope slide to remove the mucosa. Samples were also removed from the apex of the spiral colon and flushed, and all tissues were immediately flash-frozen in liquid $\mathrm{N}_{2}$ and stored at $-80^{\circ} \mathrm{C}$ until further analyses.

\section{Disappearance of ${ }^{3} \mathrm{H}$-glycy/sarcosine}

Sampled perfusate $(100 \mu \mathrm{l})$ was added to $4 \mathrm{ml}$ Scintiverse (Fisher Scientific) for liquid scintillation counting. The specific radioactivity was calculated as the mean $\mathrm{dpm} / \mu \mathrm{mol}$ of glycylsarcosine present in the perfusate. Specific radioactivity was calculated at baseline (prior to perfusion) and in each of the perfusate samples taken over the course of the $2 \mathrm{~h}$ study. The specific radioactivity was then used to determine the total quantity of glycylsarcosine. Rate of disappearance of glycylsarcosine was determined via AUC using GraphPad Prism 4.0 (Graph pad Software Inc.). Perfusates were also derivatised with phenylisothiocyanate and analysed using $\mathrm{HPLC}^{(23)}$ complete fraction collection to determine whether the isotope was associated with glycylsarcosine, glycine or some other metabolite.

\section{Disaccharidase activity}

Mucosal tissue scraped from each of the gut loop segments was analysed for sucrase and maltase activity, as per the method of Dahlqvist ${ }^{(24)}$.

\section{Real-time RT-PCR}

PepT1 mRNA was measured in mucosa sampled from each of the perfused intestinal loops. Samples of colon were also analysed. RNA was extracted using the Qiagen RNEasy 
Mini kit (Qiagen), according to the manufacturer's protocol. Relative concentration and purity were determined by measuring the absorbance at 260 and $280 \mathrm{~nm}$ using a NanoDrop 1000 (NanoDrop Technologies) spectrophotometer. RNA integrity was visualised via agarose gel visualisation of the 28S:18S ratio. Complementary DNA was created according to the protocol outlined in the QuantiTect (Qiagen) RT manual. A measure of $1 \mu \mathrm{g}$ of total RNA was used in the reverse transcription reaction. Taqman probes were utilised in the PCR. The sequences of the primers and probes were as follows: PepT1 forward primer 5'-d CTGGAGTTCTCCTATTCTCA-3', reverse primer $5^{\prime}$-d AACAGCCACGGTCAACAG-3', probe sequence for PepT1 5'-d BHQ-2-TCCTTCCAACATGAAGTCGGTGC-Pulsar 650-3'. $\beta$-Actin was used as an internal control with the following sequences: forward primer $5^{\prime}-\mathrm{d}$ CCCAGCACGATGAAGA- $3^{\prime}$, reverse primer $5^{\prime}$-d CGATCCACACGGAGTC- $3^{\prime}$, probe $5^{\prime}$-d FAM-TCAAGATCATCGCGCCTCCAGA-BHQ-1-3'. The accession numbers for the template sequences were AY180903.1 for PepT1 ${ }^{(25)}$ and AY55069 for $\beta$-actin. The Lightcycler (Roche) was set to the following conditions: $15 \mathrm{~min}$ at $95^{\circ} \mathrm{C}$, forty cycles of $1 \mathrm{~min}$ at $95^{\circ} \mathrm{C}$ and $1 \mathrm{~min}$ at $55^{\circ} \mathrm{C}$ and a $40^{\circ} \mathrm{C}$ incubation for $1 \mathrm{~min}$. Reaction efficiency for PepT1 was 0.94 (SD 0.03) and $\beta$-actin reaction efficiency was 0.96 (SD 0.06). Each sample was run in triplicate and analysed using the Livak method $\left(2^{-\mathrm{dd} C_{\mathrm{t}}}\right)^{(26)}$.

\section{Statistical analyses}

Data were analysed by one-way ANOVA with Bonferroni's protected means separation test for PepT1 mRNA. For overall uptake of glycylsarcosine, a mixed model two-way ANOVA was used, with intestinal location as the repeated measure variable; age was the second variable and age $\times$ location inter-

(A)

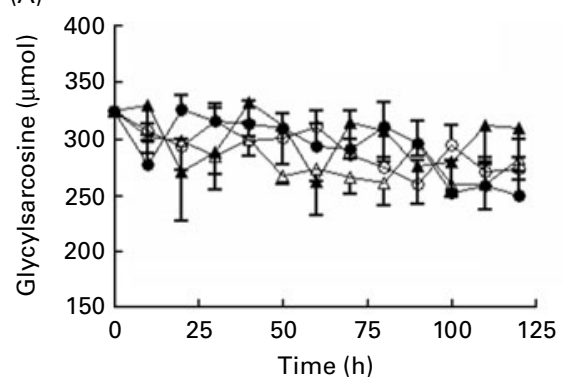

(C)

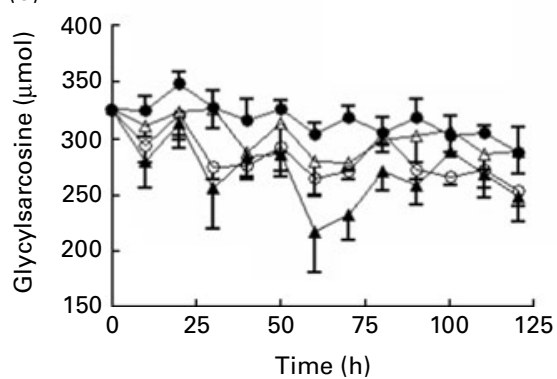

action was also reported. Glycylsarcosine uptake data over time were tested for linearity using regression analysis. Correlations between disaccharidase activity and glycylsarcosine uptake were determined by linear regression analysis. Sample size was $n 4$ piglets per age group and differences were noted as significant if $P<0.05$ (GraphPad Prism 4.0).

\section{Results}

Throughout the perfusion studies, all piglets remained stable, well-oxygenated and maintained a core body temperature above $37 \cdot 5^{\circ} \mathrm{C}$

\section{Dipeptide disappearance}

At the end of each perfusion study ( $2 \mathrm{~h}$ ), a sample of perfusate from all intestinal segments was analysed to confirm the integrity of the dipeptide. The proportion of ${ }^{3} \mathrm{H}$ associated with glycylsarcosine accounted for greater than $90 \%$ of the radioactivity in the perfusates, while glycine contained less than $5 \%$ of the label. Thus, the dipeptide did not degrade intraluminally and was available for transport. Glycylsarcosine transport occurred linearly in all intestinal loops in all the animals studied, except in the most distal loop (75\%) in piglets aged 1 and 3 weeks, and in the $0 \%$ loop in piglets aged 6 weeks (Fig. 1). In order to assess how dipeptide uptake might change along the longitudinal axis of the small intestine as the animal ages, we compared glycylsarcosine uptake between age groups at the four sites of the small intestine (Fig. 2). Overall, there was a significant effect of age $(P<0 \cdot 0001)$, intestinal location $(P=0 \cdot 001)$ and age $\times$ location interaction $(P=0.0002)$. When compared by intestinal location, dipeptide uptake was remarkably consistent at the
(B)

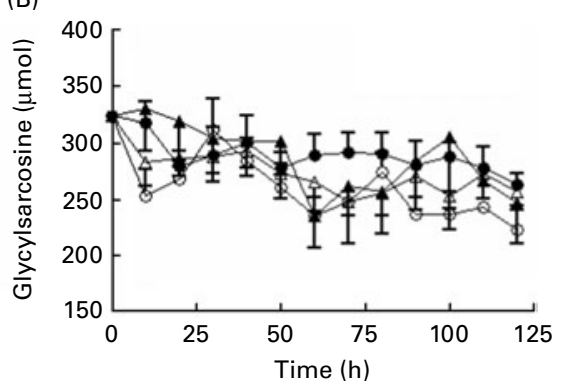

(D)

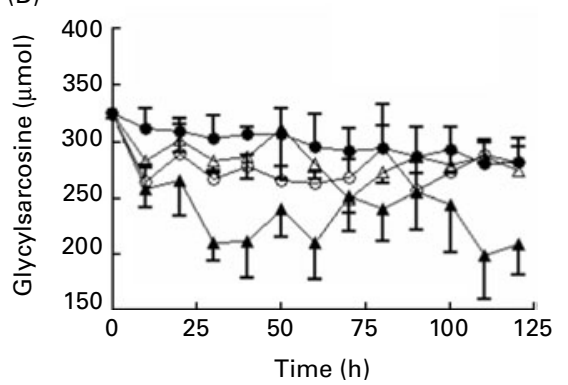

Fig. 1. Total glycylsarcosine disappeared from closed loops of small intestine during the $2 \mathrm{~h}$ perfusion study. Position of each intestinal loop is indicated by its relative position from the ligament of Treitz: (A) $0,(B) 25,(C) 50$ and (D) $75 \%$. Values are means with their standard errors $(n 4$ for each group). $\ominus$, Week 1 ; - - week $2 ; \AA$, week 3 ; $₫$-, week 6. 
most proximal site $(0 \%)$ across all age groups. At the mid-jejunum site (25\%), glycylsarcosine uptake in 1-week-old pigs was twice that in pigs aged 2 and 3 weeks $(P<0 \cdot 01)$ with 6 -week-old pigs being intermediate. During the suckling phase (weeks 1, 2 and 3), sucrase activity negatively correlated with glycylsarcosine uptake only in the mid-jejunum (25\%) $\left(r^{2} 0.59, P=0.006\right)$; at the same site, maltase activity also tended to negatively correlate with glycylsarcosine uptake $\left(r^{2} 0 \cdot 29, P=0 \cdot 09\right)$ (data not shown). In the distal jejunum $(50 \%)$, greater uptake occurred in the post-weaning animals (6 weeks) compared with the 2-week-old animals $(P<0.001)$, with uptake in piglets at 1 or 3 weeks of age being intermediate. The uptake of glycylsarcosine in the ileum (75\%) for 6-week-old animals was about twice that for piglets aged 2 and 3 weeks $(P<0 \cdot 001)$, and $30 \%$ greater than piglets at 1 week of age $(P<0.05)$. Within age groups, 1 -week-old animals had the greatest uptake in mid-jejunum and ileum $(P<0 \cdot 01)$. In 6 -week-old animals, there was a notable gradient of glycylsarcosine uptake, with the lowest uptake in the proximal jejunum and up to a 3-fold higher uptake in the ileum (Fig. 2).

\section{Quantification of PepT1 mRNA in the intestine}

Samples from all the small-intestinal segments were analysed for PepT1 mRNA, but the results were highly variable and no significant differences in PepT1 mRNA were detected between the age groups or across the length of the intestine (data not shown). PepT1 mRNA was detected in the colon of all animals (Fig. 3); however, the quantity was approximately $10 \%$ of that measured in the proximal jejunum of piglets at 1 week of age and approximately $2 \%$ of that found in the proximal jejunum of post-weaning animals $(P<0.05)$.

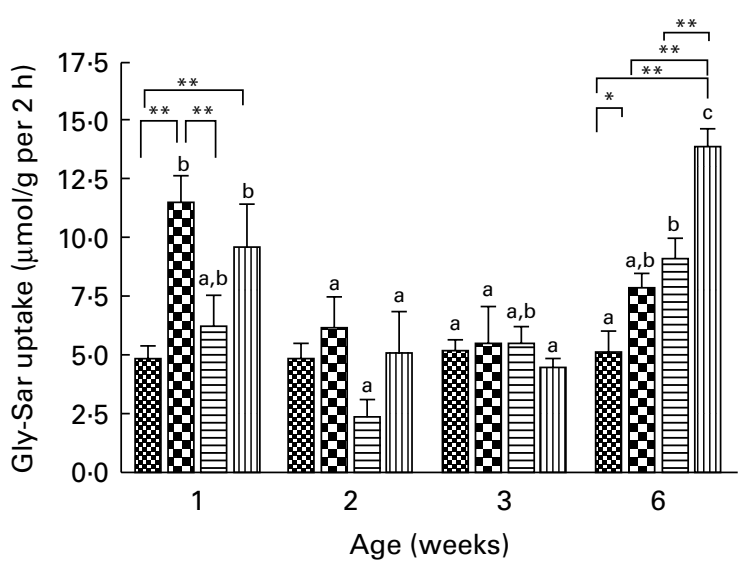

Fig. 2. Rate of glycylsarcosine uptake from closed loops of small intestine. Uptake was determined by measuring the disappearance of ${ }^{3} \mathrm{H}$-glycylsarcosine per $g$ of wet mucosa. Values are means with their standard errors ( $n 4$ for each bar) and were analysed by two-way ANOVA. Significant effects of age $(P<0.0001)$, intestinal location $(P<0.005)$ and age $\times$ location interaction $(P<0.001)$ were observed. Lines represent significant differences between intestinal sections within an age group $\left({ }^{*} P<0.05,{ }^{* *} P<0.01\right)$. $a, b, c$ Mean values with unlike superscript letters were significantly different $(P<0.05)$ within each specific intestinal site, compared between age groups. Position of each intestinal loop is indicated by its relative position from the ligament of Treitz (0 (⿴囗大) $), 25(\mathbf{⿴ 囗 十 )}), 50$ (目) and $75 \%$ (四) of the total small intestinal length).

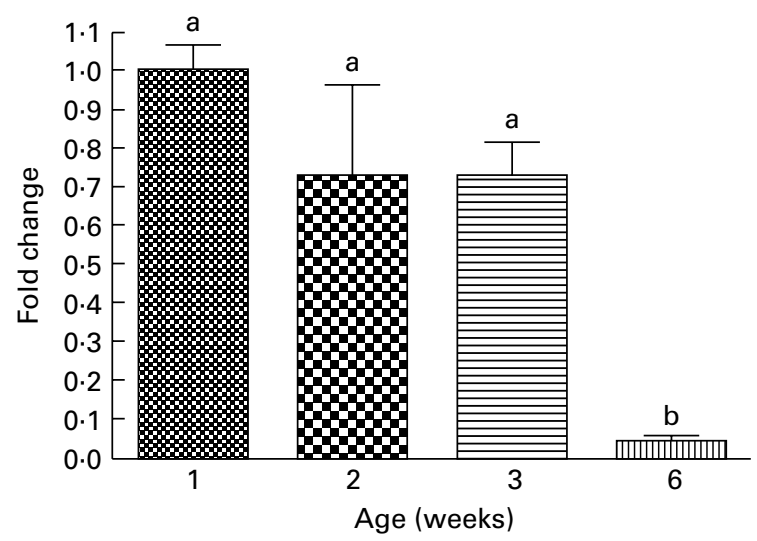

Fig. 3. Real-time RT-PCR analysis of PepT1 mRNA in the colon. Values are means with their standard errors ( $n 4$ for each bar) and were analysed by one-way ANOVA. ${ }^{a, b}$ Mean values with unlike superscript letters were significantly different $(P<0.05)$.

Although present in similar abundance at ages of 1,2 and 3 weeks, colonic PepT1 mRNA in post-weaned pigs was up to $90 \%$ lower than that in suckling pigs $(P=0 \cdot 0017)$ (Fig. 3).

\section{Discussion}

Although the porcine peptide transporter has been cloned and characterised $^{(25)}$, there has been little investigation into the ontogeny of porcine PepT1. The objective of the present study was to evaluate the ontogenic pattern in peptide transport capability and PepT1 mRNA quantity in the small intestine of the Yucatan miniature pig as it develops from suckling to a post-weaned state. Clinically, such information is necessary to appropriately design feeding regimens for infants. This objective was accomplished through the use of a hydrolysisresistant dipeptide tracer, ${ }^{3} \mathrm{H}$-glycylsarcosine, and real-time RT-PCR for mRNA analysis. From these techniques, it was determined that there was little variation in the uptake of glycylsarcosine at any location in the small intestine during the suckling period; however, in the post-weaning period, there was a distinct gradient in rate of uptake, which was greatest in the distal small intestine. Small-intestinal PepT1 mRNA was extremely variable at all locations measured in the small intestine at each age, whereas colonic PepT1 abundance declined dramatically after the animals were weaned.

In the present study, small-intestinal loops were perfused with a dipeptide-containing solution and uptake was calculated from the disappearance of ${ }^{3} \mathrm{H}$-glycylsarcosine. This in situ model is ideal to isolate specific regions of the intestine for study by allowing multiple loops per animal, limiting systemic effects of the perfusate and still maintaining first-pass metabolism ${ }^{(27-29)}$. For these reasons, this model was selected to examine dipeptide uptake in the neonatal piglet.

Absorption of glycylsarcosine and PepT1 mRNA was detected in the loops at all four locations in the small intestine. There was a significant effect of intestinal location on the uptake of the dipeptide glycylsarcosine, particularly in post-weaning pigs (Fig. 2), whereas in the older suckling animals (weeks 2 and 3), the uptake of glycylsarcosine was relatively consistent in all intestinal locations studied. The difference in diet composition 
may be responsible as the protein components of sow milk are readily digested and absorbed predominantly in the proximal parts of the small intestine ${ }^{(30,31)}$. In contrast, products of protein hydrolysis from grain-based diets, with lower digestibility consumed by weaned animals, would probably reach the ileum before absorption ${ }^{(32)}$, providing a substrate for PepT1 and perhaps a stimulus for PepT1 up-regulation in the distal intestine of the post-weaned piglet. In this respect, the distal ileum may be important for optimal nitrogen absorption in the period immediately following a diet transition. Alternatively, the transition to solid feeding can be considered a period of intestinal injury and inflammation for the milk-fed piglet ${ }^{(33,34)}$, and such injury could lead to a stimulation of peptide uptake capacity ${ }^{(35)}$. With respect to age, dipeptide uptake tended to follow a U-shaped curve, with higher uptake in 1-week-old and postweaned piglets. To determine whether dipeptide uptake is developmentally regulated, we correlated the data from the suckling period with intestinal sucrase and maltase activities. Disaccharidase activity is an established marker of intestinal maturation, and sucrase and maltase activities are known to rise significantly in piglets at about the second week of life ${ }^{(36)}$. Because dipeptide uptake negatively correlated with sucrase activity in suckled piglets, PepT1 appears to be developmentally regulated during early neonatal life, but may respond to dietary changes post-weaning.

Although PepT1 is present in the small intestine, we have also identified its presence in the colon of the developing piglet. The present results demonstrated that PepT1 mRNA is present in colonic tissues until after weaning occurs (week 6). This could be an adaptive response that occurs post-weaning; as the distal small intestine increases its capacity for oligopeptide absorption, the colon reduces the transcription of PepT1 mRNA. Shen et al. ${ }^{(10)}$ reported that PepT1 presence in the colon was transient, because by day 7 no PepT1 mRNA was found in the colon of developing rats. PepT1 has been found in the colon of rats at later time points ${ }^{(37)}$, but its presence has been primarily related to a state of intestinal injury such as gut resection. PepT1 has also been detected in the colon of human subjects who have undergone intestinal resection $^{(38)}$. PepT1 is present in the colon of human subjects with inflammatory bowel disease ${ }^{(39)}$, and it has been shown that PepT1 is capable of transporting N-formyl-methionylleucyl-phenylalarine (FMLP), which is a bacterial peptide. As such, PepT1 may be responsible for the exacerbation of inflammatory bowel disease. Colonic PepT1 mRNA and protein were also higher in patients with massive bowel resections, when compared with control subjects ${ }^{(38)}$. A study in rats demonstrated an increase in PepT1 protein in the colon of animals with intestinal resection that were fed chow ${ }^{(37)}$, whereas rats fed an elemental diet did not express any PepT1 mRNA in the colonic tissues ${ }^{(40)}$. Findings such as these underscore the importance of peptide presence in the lumen of the colon for the induction of PepT1. Although colonic peptide transport is extremely low when compared with the whole small intestine, in the event of intestinal injury or malnutrition, capacity for oligopeptide uptake may be increased through the up-regulation of PepT1, thereby recovering nutritionally valuable substrates. Whether this also leads to a greater uptake of pathogenic bacterial peptides remains to be determined.

To understand the potential impact of peptide transport, it is important to consider the variable affinity of PepT1 substrates. Alanylalanine, for example, has a high affinity for PepT1 ( $K_{\mathrm{i}}$ of 0.08 (SEM 0.01) mm), whereas glycylsarcosine is classified as a medium-affinity substrate with a $K_{\mathrm{i}}$ of $1 \cdot 1($ SEM $0 \cdot 1) \mathrm{mm}$, determined in Caco-2 cells ${ }^{(41,42)}$. Previous work on glycylsarcosine transport in porcine jejunum, using an Ussing chamber system, demonstrated dipeptide uptake of approximately $600 \mathrm{nmol} / \mathrm{cm}^{2}$ per $2 \mathrm{~h}$ (modified from Winckler et $a l .{ }^{(43)}$ ). In the present study, using the more physiological ligated loop model, we found that the overall average glycylsarcosine uptake was $424\left(\operatorname{sem~146)~} \mathrm{nmol} / \mathrm{cm}^{2}\right.$ per $2 \mathrm{~h}$. Thus, the data from the present in situ model are comparable with the previous in vitro findings using the same non-nutritional dipeptide and probably underestimate the transport rates of dietary dipeptides with higher PepT1 transporter affinity.

There are two possible mechanisms for the intestinal transport of oligopeptides: PepT1-mediated transcellular transport ${ }^{(1)}$ and paracellular transport ${ }^{(44)}$. The role of these pathways in intestinal oligopeptide transport is not yet fully understood, and there is increasing evidence that the paracellular pathway may be of some importance in the absorption of small peptides and peptidomimetic drugs ${ }^{(45,46)}$. It has been well-documented that the small intestine of suckling animals demonstrates greater paracellular transport at younger ages ${ }^{(47,48)}$. For this reason, paracellular transport could potentially mask low PepT1 activity in the young piglets that we studied (weeks 1, 2 and 3); however, the impact of paracellular transport would decrease as the animal ages. We observed the greatest disappearance of glycylsarcosine in the ileum of the post-weaning animals. Overall, if paracellular transport had significant impact on the transport of glycylsarcosine in our piglets, it would have been most prominent at the younger ages (weeks 1, 2 and 3) rather than the post-weaning state. Nevertheless, future studies characterising the contribution of paracellular transport to dietary dipeptide uptake are warranted.

In summary, we have examined the ontogenic changes of the peptide transporter PepT1 in a piglet model of the developing intestine. These results have demonstrated that the capacity for dipeptide transport is present in both the proximal and distal small intestine, with the colon potentially being able to transport peptides during the suckling state. By post-weaning, the ileum is the site of highest dipeptide uptake. The importance of dipeptides to the nutritional status of the developing infant is still unknown; however, when therapeutic formulas are necessary, it is likely that the provision of all or part of the nitrogen as small peptides conveys advantages over preparations of free amino acids, and this may be of particular importance when compromised intestinal function is present.

\section{Acknowledgements}

The present study was supported in part by a grant from the Natural Sciences and Engineering Research Council of Canada (grant number 261557-2006 RGPIN). The authors 
are solely responsible for the work described in the present article. J. A. B. and R. F. B. were responsible for project development. M. G. N. conducted the experiments, the analytical work and generated the results. All authors were involved in the statistical analyses, data interpretation and writing of the manuscript. The authors declare that they have no conflict of interest.

\section{References}

1. Daniel H (2004) Molecular and integrative physiology of intestinal peptide transport. Annu Rev Physiol 66, 361-384.

2. Chen H, Wong EA \& Webb KE Jr (1999) Tissue distribution of a peptide transporter mRNA in sheep, dairy cows, pigs and chickens. J Anim Sci 77, 1277-1283.

3. Li H, Gilbert ER, Zhang Y, et al. (2008) Expression profiling of the solute carrier gene family in chicken intestine from the late embryonic to early post-hatch stages. Anim Genet 39, 407-424.

4. Wang W, Shi C, Zhang J, et al. (2008) Molecular cloning, distribution and ontogenetic expression of the oligopeptide transporter PepT1 mRNA in Tibetan suckling piglets. Amino Acids 37, 593-601.

5. Lu H \& Klassen C (2006) Tissue distribution and thyroid hormone regulation of Pept 1 and Pept 1 mRNA in rodents. Peptides 27, 850-857.

6. Rome S, Barbot L, Windsor E, et al. (2002) The regionalization of PepT1, NBAT and EAAC1 transporters in the small intestine of rats are unchanged from birth to adulthood. J Nutr 132, 1009-1011.

7. Erickson RH, Gum JR Jr, Lindstrom MM, et al. (1995) Regional expression and dietary regulation of rat small intestinal peptide and amino acid transporter mRNAs. Biochem Biophys Res Commun 216, 249-257.

8. Terada T, Shimada Y, Pan X, et al. (2005) Expression profiles of various transporters for oligopeptides, amino acids and organic ions along the human digestive tract. Biochem Pharm 70, 1756-1763.

9. Herrera-Ruiz D, Wang Q, Gudmundsson OS, et al. (2001) Spatial expression patterns of peptide transporters in the human and rat gastrointestinal tracts, Caco-2 in vitro cell culture model, and multiple human tissues. AAPS PharmSci 3, E9.

10. Shen H, Smith DE \& Brosius FC III (2001) Developmental expression of PEPT1 and PEPT2 in rat small intestine, colon, and kidney. Pediatr Res 49, 789-795.

11. Chen H, Pan YX, Wong EA, et al. (2005) Dietary protein level and stage of development affect expression of an intestinal peptide transporter (cPepT1) in chickens. J Nutr $\mathbf{1 3 5}$, 193-198.

12. Gilbert ER, Li H, Emmerson DA, et al. (2007) Developmental regulation of nutrient transporter and enzyme mRNA abundance in the small intestine of broilers. Poult Sci $\mathbf{8 6}$, 1739-1753.

13. D'Inca R, Gras-Le Guen C, Che L, et al. (2011) Intrauterine growth restriction delays feeding-induced gut adaptation in term newborn pigs. Neonatology 99, 208-216.

14. Ganapathy V, Brandsch M \& Leibach FH (1994) Intestinal transport of amino acids and peptides. In Physiology of the Gastrointestinal Tract, pp. 261-277 [LR Johnson, editor]. New York, NY: Raven Press.

15. Steinhardt HJ \& Adibi SA (1986) Kinetics and characteristics of absorption from an equimolar mixture of 12 glycyldipeptides in human jejunum. Gastroenterology $\mathbf{9 0}$, $577-582$.
16. Boza JJ, Moënnoz D, Vuichoud J, et al. (2000) Protein hydrolysate vs free amino acid-based diets on the nutritional recovery of the starved rat. Eur J Nutr 39, 237-243.

17. Henderson TR, Hamosh M, Armand M, et al. (2001) Gastric proteolysis in preterm infants fed mother's milk or formula. Adv Exp Med Biol 501, 403-408.

18. Austic R (1985) Development and adaptation of protein digestion. J Nutr 115, 686-697.

19. Lima NL, Soares AM, Mota RM, et al. (2007) Wasting and intestinal barrier function in children taking alanylglutamine-supplemented enteral formula. J Pediatr Gastroenterol Nutr 44, 365-374.

20. Alteheld B, Evans ME, Gu LH, et al. (2005) Alanylglutamine dipeptide and growth hormone maintain PepT1-mediated transport in oxidatively stressed Caco-2 cells. J Nutr $\mathbf{1 3 5}$, $19-26$.

21. Silk DB, Hegarty JE, Fairclough PD, et al. (1982) Characterization and nutritional significance of peptide transport in man. Ann Nutr Metab 26, 337-352.

22. Shulman RJ (1993) The piglet can be used to study the effects of parenteral and enteral nutrition on body composition. J Nutr 123, 395-398.

23. Bidlingmeyer BA, Cohen SA \& Tarvin TL (1984) Rapid analysis of amino acids using pre-column derivatization. J Chromatogr 336, 93-104.

24. Dahlqvist A (1968) Assay of intestinal disaccharidases. Anal Biochem 22, 99-107.

25. Klang JE, Burnworth LA, Pan YX, et al. (2005) Functional characterization of a cloned pig intestinal peptide transporter (pPepT1). J Anim Sci 83, 172-181.

26. Livak KJ \& Schmittgen TD (2001) Analysis of relative gene expression data using real-time quantitative PCR and the 2(-Delta Delta $C(\mathrm{~T})$ ) method. Methods 25, 402-408.

27. Nichols NL \& Bertolo RF (2008) Luminal threonine concentration acutely affects intestinal mucosal protein and mucin synthesis in piglets. J Nutr 138, 1298-1303.

28. Adegoke OAJ, McBurney MI \& Baracos VE (1999) Jejunal mucosal protein synthesis: validation of luminal flooding dose method and effect of luminal osmolarity. Am J Physiol 276, G14-G20.

29. Adegoke OAJ, McBurney MI, Samuels SE, et al. (1999) Luminal amino acids acutely decrease intestinal mucosal protein synthesis and protease mRNA in piglets. J Nutr 129, 1871-1878.

30. Mavromichalis I, Parr TM, Gabert VM, et al. (2001) True ileal digestibility of amino acids in sow's milk for 17-day-old pigs. J Anim Sci 79, 707-713.

31. Buddington RK, Elnif J, Puchal-Gardiner AA, et al. (2001) Intestinal apical amino acid absorption during development of the pig. Am J Physiol Regul Integr Comp Physiol 280, R241-R247.

32. Low AG (1979) Studies on digestion and absorption in the intestines of growing pigs. 6. Measurements of the flow of amino acids. Br J Nutr 41, 147-156.

33. Moeser AJ, Klok CV, Ryan KA, et al. (2007) Stress signaling pathways activated by weaning mediate intestinal dysfunction in the pig. Am J Physiol Gastrointest Liver Physiol 292, G173-G181.

34. Pié S, Lallès JP, Blazy F, et al. (2004) Weaning is associated with an upregulation of expression of inflammatory cytokines in the intestine of piglets. J Nutr 134, 641-647.

35. Vavricka SR, Musch MW, Fujiya M, et al. (2006) Tumor necrosis factor-alpha and interferon-gamma increase PepT1 expression and activity in the human colon carcinoma cell line Caco-2/bbe and in mouse intestine. Pflugers Arch $\mathbf{4 5 2}$, $71-80$. 
36. James PS, Smith MW, Tivey DR, et al. (1987) Epidermal growth factor selectively increases maltase and sucrase activities in neonatal piglet intestine. J Physiol 393, 583-594.

37. Shi B, Song D, Xue H, et al. (2006) Abnormal expression of the peptide transporter PepT1 in the colon of massive bowel resection rat: a potential route for colonic mucosa damage by transport of fMLP. Dig Dis Sci 51, 2087-2093.

38. Ziegler TR, Fernández-Estívariz C, Gu LH, et al. (2002) Distribution of the $\mathrm{H}^{+}$/peptide transporter PepT1 in human intestine: up-regulated expression in the colonic mucosa of patients with short-bowel syndrome. Am J Clin Nutr 75, 922-930.

39. Merlin D, Si-Tahar M, Sitaraman SV, et al. (2001) Colonic epithelial hPepT1 expression occurs in inflammatory bowel disease: transport of bacterial peptides influences expression of MHC class 1 molecules. Gastroenterology 120, 1666-1679.

40. Lardy H, Thomas M, Noordine ML, et al. (2006) Changes induced in colonocytes by extensive intestinal resection in rats. Dig Dis Sci 51, 326-332.

41. Brandsch M, Thunecke F, Küllertz G, et al. (1998) Evidence for the absolute conformational specificity of the intestinal $\mathrm{H}^{+} /$peptide symporter, PEPT1. J Biol Chem 273, 3861-3864.
42. Brandsch M, Knütter I, Thunecke F, et al. (1999) Decisive structural determinants for the interaction of proline derivatives with the intestinal $\mathrm{H}^{+}$/peptide symporter. Eur J Biochem 266, 502-508.

43. Winckler C, Breves G, Boll M, et al. (1999) Characteristics of dipeptide transport in pig jejunum in vitro. J Comp Physiol B 169, 495-500.

44. McCollum MQ \& Webb KE Jr (1998) Glycyl-L-sarcosine absorption across ovine omasal epithelium during coincubation with other peptide substrates and volatile fatty acids. J Anim Sci 76, 2706-2711.

45. Lafforgue G, Arellano C, Vachoux C, et al. (2008) Oral absorption of ampicillin: role of paracellular route vs. PepT1 transporter. Fundam Clin Pharmacol 22, 189-201.

46. Menon RM \& Barr WH (2003) Comparison of ceftibuten transport across Caco-2 cells and rat jejunum mounted on modified Ussing chambers. Biopharm Drug Dispos 24, 299-308.

47. Udall JN, Pang K, Fritze L, et al. (1981) Development of gastrointestinal mucosal barrier. I. The effect of age on intestinal permeability to macromolecules. Pediatr Res 15, 241-244.

48. Weaver LT, Laker MF \& Nelson R (1984) Intestinal permeability in the newborn. Arch Dis Child 59, 236-241. 